Vol. 14 (2005): 70-82.

\title{
An analytical procedure for determination of sulphur species and isotopes in boreal acid sulphate soils and sediments
}

\author{
Krister Backlund, Anton Boman \\ Åbo Akademi University, Department of Geology and Mineralogy, FI-20500 Turku, Finland, \\ e-mail:krister.backlund@abo.fi,anton.boman@abo.fi \\ Sören Fröjdö \\ Åbo Akademi University, Department of Geology and Mineralogy, FI-20500 Turku, Finland \\ Mats Åström \\ Department of Biology and Environmental Science, Kalmar University, SE-39182 Kalmar, Sweden
}

\begin{abstract}
An analytical scheme suitable for boreal acid sulphate (AS) soils and sediments was developed on the basis of existing methods. The presented procedure can be used to quantify and discriminate among acid volatile sulphide, cold chromium reducible sulphur, hot chromium reducible sulphur, elemental sulphur, sulphate sulphur, organic sulphur, total reducible sulphur and total sulphur. The sulphur fractions are recovered as either $\mathrm{Ag}_{2} \mathrm{~S}$ or $\mathrm{BaSO}_{4}$ precipitates and can further be used for isotope analysis.

Overlaps between sulphur species are common during speciation, and must be minimized. Some of these overlaps are caused by poor sampling and storage, inappropriate conditions during the distillation, or natural variations in the sample (e.g. $\mathrm{Fe}^{3+}$ interference and grain size). The procedural impact was determined by conducting tests on both artificial and natural samples containing one or several sulphur species. The method is applied on reduced sediment from an AS soil locality (Överpurmo) and a brackish lake (Larsmo Lake) in western Finland and the results, including S-isotopes, are discussed.
\end{abstract}

Key words: sulphur species, sulphur isotopes, analytical scheme, acid sulphate soils, sediment

\section{Introduction}

Acid sulphate (AS) soils occupy large areas of the tropical and subtropical coasts of Asia, Africa,
Australia, and significant areas along the boreal coastal plains of Finland and Sweden (Palko 1994, Öborn 1994, Joukainen and Yli-Halla 2003). AS soils constitute a major environmental problem due to the release of acidity and metals during oxi- 
Vol. 14 (2005): 70-82.

dation of naturally occurring sulphur species (e.g. Åström 2001, Sundström et al. 2002). According to van Breemen (1973) potential AS soils commonly contain pyrite sulphur $\left(\mathrm{FeS}_{2}\right)$ between 1 and $4 \%$, and ferrous monosulphides (FeS) comprise less than $0.01 \%$ and rarely exceed $0.6 \%$ even in reduced black muds. However, in black clays in north-eastern Sweden FeS comprises a significant amount (up to $80 \%$ ) of the total sulphur (Georgala 1980). Iron sulphides are usually divided into two categories: (1) acid volatile sulphide (AVS) and (2) disulphides $\left(\mathrm{FeS}_{2}\right)$. AVS consists of amorphous $\mathrm{FeS}$, mackinawite $\left(\mathrm{FeS}_{0.94}\right)$, greigite $\left(\mathrm{Fe}_{3} \mathrm{~S}_{4}\right)$ (Morse et al. 1987), dissolved sulphide (Morse and Rickard 2004), and amorphous monosulphides of other metals (e.g. zinc, cadmium or lead) (Lasorsa and Casas 1996, Morse and Luther 1999), while disulphides include pyrite (cubic $\mathrm{FeS}_{2}$ ) and marcasite (orthorhombic $\mathrm{FeS}_{2}$ ) (Rice et al. 1993). Elemental sulphur $\left(\mathrm{S}^{0}\right)$ generally occurs in small quantities (usually $<2 \%$ of total sulphur) in reduced marine muds and may be produced by oxidation of FeS, $\mathrm{FeS}_{2}$ and $\mathrm{H}_{2} \mathrm{~S}$ (van Breemen 1973, Poulton et al. 2004). Organic sulphur is generally the most abundant sulphur species in normal soils, but in pyritebearing sediments and AS soils it is usually quantitatively insignificant (van Breemen 1973). For example, Georgala (1980) estimated that organic sulphur constituted less than $0.03 \mathrm{wt} \%$ in black clays from north-eastern Sweden. Sulphate is usually not present in large quantities in reduced sediment, but in AS soils, a large number of sulphate minerals can be found in association with oxidation of mainly pyritic material. Most of these sulphate compounds are water soluble and only persist in the absence of leaching (van Breemen 1973).

Different forms of sulphur have previously been separated and quantified by various techniques (e.g. Zhabina and Volkov 1978, Nriagu and Soon 1985, Canfield et al. 1986, Tuttle et al. 1986, Hall et al. 1988, Fossing and Jørgensen 1989, Bates et al. 1993, Rice et al. 1993, Duan et al. 1997, Sullivan et al. 2000, Kallmeyer et al. 2004). At present, most of the sulphur speciation methods are based on the sequential extraction scheme that Zhabina and Volkov introduced in 1978, where iron monosulphides are digested in $\mathrm{HCl}$ and iron disulphides are reduced by $\mathrm{Cr}^{2+}$ in an acidic solution. Elemental sulphur is commonly determined by dissolution with an organic solvent, followed by a Cr-reduction. The evolved $\mathrm{H}_{2} \mathrm{~S}$ can be determined gravimetrically as $\mathrm{Ag}_{2} \mathrm{~S}, \mathrm{ZnS}$ or $\mathrm{CdS}$ (e.g. Zhabina and Volkov 1978, Tuttle et al. 1986, Di Toro et al. 1990, Bates et al. 1993), by EDTA titration (Newton et al. 1995), iodometrically, spectrophotometrically, polarographically, or by ICP-MS (Zhabina and Volkov 1978, Allen and Parkes 1995). Determination of reduced sulphur is performed under anoxic conditions, which can be obtained by using $\mathrm{N}_{2}, \mathrm{CO}_{2}$ or $\mathrm{Ar}$ (Zhabina and Volkov 1978, Hall et al. 1988). Sulphate is usually precipitated as $\mathrm{BaSO}_{4}$ after separation of AVS (e.g. Nriagu and Soon 1985, Tuttle et al. 1986, Hall et al. 1988, Rice et al. 1993) or after removal of chromium reducible sulphur (Bates et al. 1993). Organic sulphur is commonly converted to sulphate by oxidation with Eschka's mixture and subsequently precipitated as $\mathrm{BaSO}_{4}$ (e.g. Tuttle et al. 1986, Bates et al. 1993, Rice et al. 1993).

A complete analytical scheme for the separation and quantification of sulphur species present in a sample has not yet been developed despite several efforts. In order to determine which distillation technique is most suitable it is of importance to understand how various treatments affect the sample. There are often overlaps between different sulphur phases due to: (1) oxidation of AVS to $\mathrm{S}^{0}$ during sampling/storage; (2) oxidation of $\mathrm{H}_{2} \mathrm{~S}$ to $\mathrm{S}^{0}$ during the distillation process; (3) the analytical conditions and treatments used; and (4) the grain size and crystallinity of the sulphide minerals.

The aim of this study was to develop an analytical scheme suitable for the determination of sulphur species and isotopes in boreal potential and actual AS soils and shallow coastal sediments. The development of such a scheme is important because knowledge of sulphur speciation and behaviour in these materials is inadequate to understand and model how: (1) acidity is formed in and leached from AS soils; (2) marine sediments brought above the sea level by postglacial isostatic rebound (up to $9 \mathrm{~mm}$ per year) are turned into highly problematic AS soils; (3) the cold climatic 
conditions affects neutralisation and formation of acidity in soils and waters; and (4) thick sediment layers uplifted above sea level are ultimately preserved black, and thus monosulphide-rich and highly reactive, when exposed to atmospheric oxygen. Finally, the intent to study the isotopic composition of each sulphur species in the samples puts additional constraints on the scheme. Firstly, distillation must be optimised in regard to the quantity and separation of species and secondly, sulphur must be extracted from each species in a form suitable for the later analysis of sulphur isotopes.

\section{Material and methods}

\section{Natural samples}

Reduced sediment from an AS soil locality (Överpurmo) and a brackish lake (Larsmo Lake) in western Finland were collected. The sediments are fine-grained and homogeneous with a clayey texture and black colour. The Överpurmo sediment, located 40 meters above the present sea level (due to isostatic land uplift), was deposited in a shallow coastal environment about 4000 years ago. Fresh samples were stored (within two hours after sampling) in a freezer in order to minimize oxidation. In the laboratory, the samples were thawed in a nitrogen-filled glove bag and any visibly oxidized surface material was removed, keeping only the un-oxidized core of the sample for subsequent analysis. Any shell fragments found in the sediments were removed before further analysis.

\section{Artificial samples}

Mixtures of finely ground sulphur minerals (pyrite and elemental sulphur) and chemical reagents $\left(\mathrm{Na}_{2} \mathrm{~S} \cdot 9 \mathrm{H}_{2} \mathrm{O}\right.$ and $\left.\mathrm{Na}_{2} \mathrm{SO}_{4}\right)$ were prepared in order to test the analytical scheme. The sulphur concentration in pyrite $\left(\mathrm{FeS}_{2}\right)$, elemental sulphur $\left(\mathrm{S}^{0}\right)$ and sodium sulphate $\left(\mathrm{Na}_{2} \mathrm{SO}_{4}\right)$ was calculated based on the molecular formula. The range of the $\mathrm{Na}_{2} \mathrm{~S}$ concentration in $\mathrm{Na}_{2} \mathrm{~S} \cdot 9 \mathrm{H}_{2} \mathrm{O}$ is $32-38 \%$ and the sulphur concentration was determined to be $13.2 \pm$ $0.003 \%$ by dissolving a known amount of $\mathrm{Na}_{2} \mathrm{~S} \cdot 9 \mathrm{H}_{2} \mathrm{O}$ in deionized water $(18.2 \mathrm{M} \Omega)$ and precipitating the sulphide as $\mathrm{Ag}_{2} \mathrm{~S}$ (assuming 100\% recovery).

\section{Sulphur speciation method - general approach}

The distillation apparatus (Fig. 1a) used for extraction of the sulphur species consists of a heating plate (with magnetic stirrer), a $500 \mathrm{ml}$ reaction flask (with injection ports for reagents and nitrogen) attached to a condenser, a $250 \mathrm{ml}$ buffer vessel (containing $200 \mathrm{ml}$ of $0.05 \mathrm{M}$ potassium hydrogen phthalate, $\mathrm{pH} 4$ ) used for preventing formation of $\mathrm{AgCl}$ in the sulphide traps and a pair of $50 \mathrm{ml}$ sulphide traps (containing $15 \mathrm{ml}$ of $0.1 \mathrm{M} \mathrm{AgNO}_{3}$ ), of which the latter is used as a safety trap only. The glassware is connected by rubber tubing.

A $\mathrm{Cr}^{2+}$ containing solution was prepared by percolating $1 \mathrm{M} \mathrm{CrCl}_{3} \cdot 6 \mathrm{H}_{2} \mathrm{O}$ in $0.5 \mathrm{M} \mathrm{HCl}$ through a Jones reductor (Fig. 1b), constructed as described by Skoog and West (1976). In this process, $\mathrm{Cr}^{3+}$ is reduced to $\mathrm{Cr}^{2+}$ which can be verified by a colour change from dark green $\left(\mathrm{Cr}^{3+}\right)$ to bright blue $\left(\mathrm{Cr}^{2+}\right)$. The solution was collected in sealed plastic syringes, where it was stable for several days.

A frozen sample was thawed in a nitrogenfilled glove bag, homogenised and divided into subsamples. One of the subsamples was dried at $105^{\circ} \mathrm{C}$ for determination of the dry weight, while the other subsamples were used for sulphur speciation. Approximately $3 \mathrm{~g}$ of wet subsample was weighed (to the nearest tenth of a milligram) into the reaction flask, and $10 \mathrm{ml}$ of ethanol was added to facilitate reflux condensation during distillation (Fossing and Jørgensen 1989). The distillation apparatus was flushed for 10 minutes with pure (99.5\%) nitrogen gas before inserting reagents for $\mathrm{H}_{2} \mathrm{~S}$ emanation, and nitrogen flowed continuously (approximately 5 bubbles per second in the buffer vessel) throughout the distillation process. Liber- 
Vol. 14 (2005): 70-82.

a)

Distillation apparatus

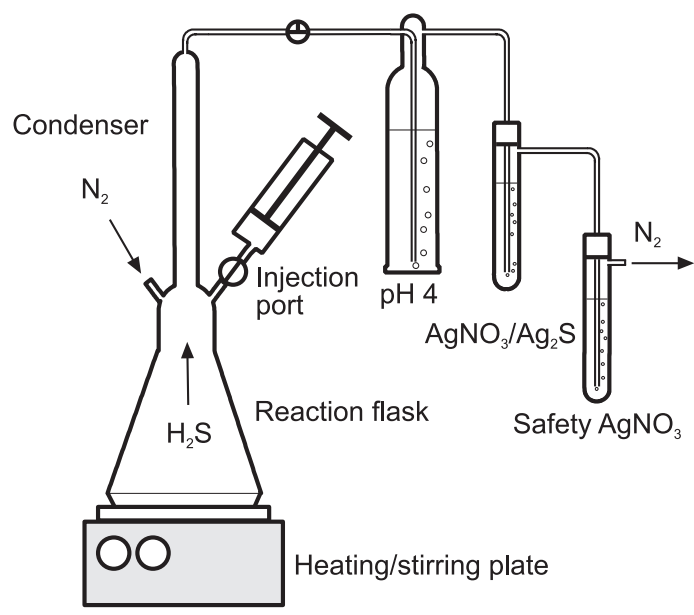

ated $\mathrm{H}_{2} \mathrm{~S}$ from reduced sulphur was transported, through the buffer solution into the sulphide trap and precipitated as $\mathrm{Ag}_{2} \mathrm{~S}$. After each reaction step was complete, the trap was replaced and distillation of another species started by addition of the appropriate reagent to the reaction flask. Deoxygenating all solutions with nitrogen before analysis minimized oxidation of $\mathrm{H}_{2} \mathrm{~S}$ during reaction. The remaining slurry in the reaction flask was filtered, and the filtrate and residue were analysed for sulphate and organic sulphur, respectively.

Precipitated $\mathrm{Ag}_{2} \mathrm{~S}$ was filtered and washed with deionized water $(18.2 \mathrm{M} \Omega$ ) on preweighed Whatman (No 42) filter papers. After drying at $105^{\circ} \mathrm{C}$ for two hours, the precipitate was cooled in a desiccator for 30 minutes. $\mathrm{BaSO}_{4}$ was filtered on $\mathrm{S} \& \mathrm{~S}$ blue ribbon $589^{3}$ filter papers and transferred to a preweighed porcelain crucible and slowly ignited ( 2 hours) to $800^{\circ} \mathrm{C}$, leaving only $\mathrm{BaSO}_{4}$. The crucible was left to cool in a desiccator for 30 minutes. Weight percents (wt\%) of sulphur were calculated from the weights of $\mathrm{Ag}_{2} \mathrm{~S}$ or $\mathrm{BaSO}_{4}$. The detection limit for $\mathrm{S}$ was estimated to be $0.01 \mathrm{wt} \%$ in a $1 \mathrm{~g}$ sample (dry weight). b)

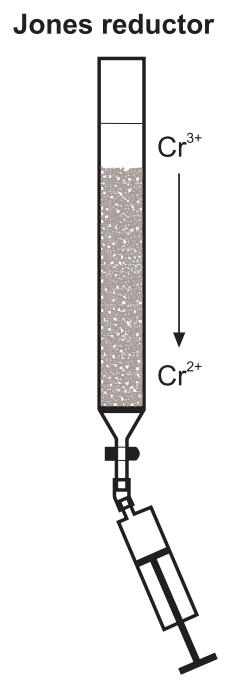

Fig. 1. A sketch of the equipment used in the speciation experiments: (a) the distillation apparatus, and (b) the Jones reductor for preparation of $\mathrm{CrCl}_{2}$ solution.

\section{Sequential extraction procedure}

An analytical scheme (Fig. 2) was devised for distinguishing AVS, cold chromium reducible sulphur (CCrS), hot chromium reducible sulphur ( $\mathrm{HCrS})$, elemental sulphur (ES), sulphate sulphur $\left(\mathrm{SO}_{4}^{2-}\right)$, organic sulphur (OrgS), total reducible sulphur (TRS) and total sulphur (TotS).

For determination of ES, a wet subsample was placed in a $15 \mathrm{ml}$ centrifuge tube together with 8 $\mathrm{ml}$ dichloromethane $\left(\mathrm{CH}_{2} \mathrm{Cl}_{2}\right)$. After 24 hours, the tube was centrifuged and the supernatant (containing dissolved ES) was transferred to a reaction flask for evaporation. Solid ES in the reaction flask was subsequently heated in $50 \mathrm{ml}$ of $6 \mathrm{M} \mathrm{HCl}$ and $50 \mathrm{ml}$ of $1 \mathrm{M} \mathrm{CrCl}_{2}$, and the concentration of ES was determined from the precipitated $\mathrm{Ag}_{2} \mathrm{~S}$. ES is thought to mainly consist of $\mathrm{S}^{0}$, but some forms of organic sulphur (e.g. organic polysulphides) may also dissolve in the organic solvent (Mossmann et al. 1991). The residue in the centrifuge tube was transferred to a reaction flask for further analyses.

The residue, or a fresh subsample if ES was not determined separately (Fig. 2), was weighed into 


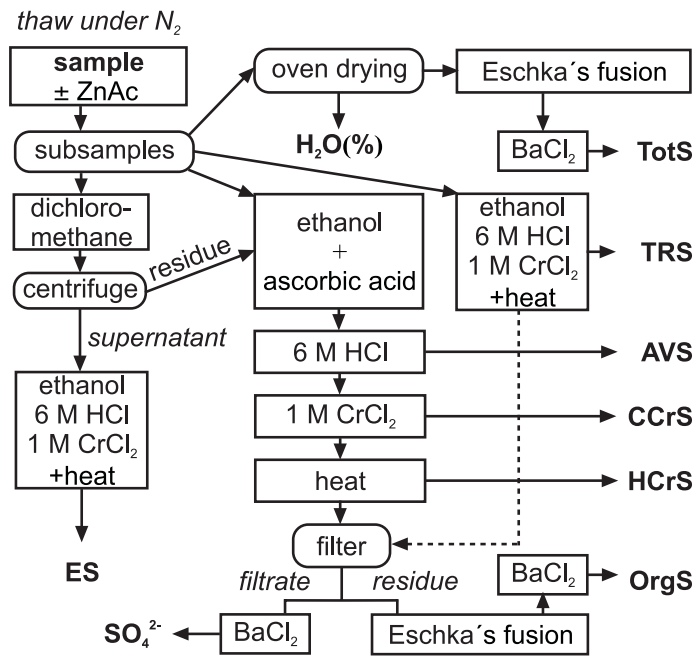

Fig. 2. Flow diagram of the analytical procedures used in this study.

the reaction flask, and $50 \mathrm{ml}$ of $6 \mathrm{M} \mathrm{HCl}$ was added for the determination of AVS. The distillation was completed after approximately two hours. According to previous studies (e.g. Morse et al. 1987) AVS is believed to comprise mainly iron monosulphides and some greigite. Different treatments and chemicals are known to affect AVS recovery, and additional experiments were performed: (1) by addition of ascorbic acid (AA); (2) by heating to boiling point; (3) by addition of $5 \mathrm{~g} \mathrm{SnCl}_{2}$; and (4) by addition of $15 \mathrm{ml} 20 \%(\mathrm{w} / \mathrm{v})$ zinc acetate (ZnAc).

After removal of AVS, $50 \mathrm{ml}$ of $1 \mathrm{M} \mathrm{CrCl}_{2}$ was added, and 4-5 hours later any CCrS, consisting of "less mature" pyrite (Duan et al. 1997) and possibly some greigite and organic polysulphides (Canfield et al. 1998), had been extracted. Thereafter the reaction flask was heated to boiling point for 1-2 hours until $\mathrm{HCrS}$ distillation was complete. $\mathrm{HCrS}$ comprises "more mature" pyrite, i.e. possibly larger grains that may be coated with cements and overgrowths (Rice et al. 1993), and ES that has not been removed prior to this stage (Duan et al. 1997). The remaining content in the reaction flask was filtered, and the filtrate was used for de- termination of dissolved $\mathrm{SO}_{4}{ }^{2-}$ and the residue for OrgS.

The filtrate was treated with $10 \mathrm{ml}$ of $30 \%$ $\mathrm{H}_{2} \mathrm{O}_{2}$ at $60^{\circ} \mathrm{C}$ in order to oxidize any organic matter in the solution. The next day the volume was reduced to $200 \mathrm{ml}$, and excess $(10 \mathrm{ml}) 10 \% \mathrm{BaCl}_{2}$ was added dropwise, while stirring, and the solution was left overnight at $60^{\circ} \mathrm{C}$ before filtering and weighing the precipitated $\mathrm{BaSO}_{4}$. The $\mathrm{SO}_{4}{ }^{2-}$ may occur in the form of acid soluble sulphate (e.g. jarosite: $\left.\mathrm{KFe}_{3}\left(\mathrm{SO}_{4}\right)_{2}(\mathrm{OH})_{6}\right)$, water soluble sulphate (e.g. gypsum: $\mathrm{CaSO}_{4}$ ) or as adsorbed sulphate (Begheijn et al. 1978).

The residue was washed with deionized water and dried at $105^{\circ} \mathrm{C}$. Approximately $1 \mathrm{~g}$ of dry residue was mixed with $3 \mathrm{~g}$ of Eschka's mixture and placed in a porcelain crucible with an additional layer of Eschka's mixture on top. The crucible was heated at $800^{\circ} \mathrm{C}$ for two hours, in order to oxidize sulphur to sulphate. The fusion residue was then transferred to a $500 \mathrm{ml}$ Erlenmeyer flask and dissolved in $200 \mathrm{ml}$ deionized water. After simmering for 30 minutes, the solution was filtered and the $\mathrm{pH}$ was adjusted to less than 4 (prevents formation of iron oxides). Excess $(10 \mathrm{ml}) 10 \% \mathrm{BaCl}_{2}$ was added dropwise, while stirring, to the filtrate $(<200 \mathrm{ml})$, and the solution was left overnight at $60^{\circ} \mathrm{C}$ before filtering and quantifying the precipitated $\mathrm{BaSO}_{4}$. The OrgS fraction extracted consists of non Cr-reducible organic sulphur, and possibly $\mathrm{BaSO}_{4}$. The Eschka's fusion can also be used to determine the total amount of sulphur in the sample (Fig. 2).

Total reduced sulphur, comprising AVS, CCrS, $\mathrm{HCrS}$ and ES, was determined on a separate subsample. After adding $50 \mathrm{ml}$ of $6 \mathrm{M} \mathrm{HCl}$ and $50 \mathrm{ml}$ of $1 \mathrm{M} \mathrm{CrCl}_{2}$ to the sample, the solution was boiled for 1-2 hours for complete distillation of TRS. The remaining slurry in the reaction flask can further be analysed for $\mathrm{SO}_{4}{ }^{2-}$ and $\mathrm{OrgS}$.

\section{Isotopic measurements}

The quantities of recovered $\mathrm{Ag}_{2} \mathrm{~S}$ or $\mathrm{BaSO}_{4}$ precipitates varied depending on the sample size, sulphur concentration and proportion of sulphur spe- 
Vol. 14 (2005): 70-82.

cies, and analysis of the isotopic composition of sulphur was not always possible. However, when sufficient material was available, standard methods were used to prepare the samples for analysis. About $40 \mathrm{mg}$ of $\mathrm{Ag}_{2} \mathrm{~S}$ (corresponding to approximately $5 \mathrm{mg}$ of sulphur) was converted to $\mathrm{SO}_{2}$ by reaction with $200 \mathrm{mg}$ cuprous oxide $\left(\mathrm{Cu}_{2} \mathrm{O}\right)$, according to the procedure by Robinson and Kusakabe (1975). The $\mathrm{BaSO}_{4}$ samples were prepared following the procedures outlined by Yanagisawa and Sakai (1983), where about $10 \mathrm{mg}$ of $\mathrm{BaSO}_{4}$ was mixed with $200 \mathrm{mg}(1: 20)$ of a $1: 1 \mathrm{~V}_{2} \mathrm{O}_{5}: \mathrm{SiO}_{2}$ mixture. The sample mixtures were placed in small quartz-glass capsules, which were introduced into an evacuated preparation line. For both sample types, the temperature was slowly raised from $300^{\circ} \mathrm{C}$ to $950^{\circ} \mathrm{C}$ during 15 minutes to ensure complete combustion. A spiral of metallic copper was placed at the mouth of the furnace in order to convert $\mathrm{SO}_{3}$ to $\mathrm{SO}_{2}$. Gas yields from combustion were monitored by a pressure gauge on a volume calibrated part of the vacuum line and samples with $\mathrm{SO}_{2}$-yields $<95 \%$ were discarded. To obtain a pure $\mathrm{SO}_{2}$ sample, $\mathrm{H}_{2} \mathrm{O}(\mathrm{g}), \mathrm{CO}_{2}(\mathrm{~g})$ and uncompressible gases were removed by distillation under high vacuum.

The $\mathrm{SO}_{2}$ was introduced into a modified VG Micromass 602 that is run by in-house software (originally developed at the Museum of Natural History in Stockholm, Sweden). The measured
${ }^{34} \mathrm{~S} /{ }^{32} \mathrm{~S}$ ratios are reported as $\delta^{34} \mathrm{~S}$ values, i.e. the parts per mil deviation of the sample relative to the ${ }^{34} \mathrm{~S} /{ }^{32} \mathrm{~S}$ ratio in the Canyon Diablo Troilite (CDT). The precision was estimated to approximately $\pm 0.3 \%$ o, and measurements on standard materials NBS-127 $\mathrm{BaSO}_{4}\left(\delta^{34} \mathrm{~S} 20.3 \mathrm{CDT}\right)$ and Göttingen $\mathrm{CdS}\left(\delta^{34} \mathrm{~S}-20.8 \mathrm{CDT}\right)$ gave $\delta^{34} \mathrm{~S}$ values of 20.34 and -21.1 , respectively.

\section{Results and discussion}

\section{Recovery of sulphur from pure phases and artificial mixtures}

In order to test the distillation technique several sulphur compounds were analysed individually and in mixtures. AVS is represented by $\mathrm{Na}_{2} \mathrm{~S} \cdot 9 \mathrm{H}_{2} \mathrm{O}$ (hereafter referred to as $\mathrm{Na}_{2} \mathrm{~S}$ ), and $\mathrm{CCrS}, \mathrm{HCrS}$ and $\mathrm{SO}_{4}{ }^{2-}$ is represented by natural pyrite $\left(\mathrm{FeS}_{2}\right)$, elemental sulphur $\left(\mathrm{S}^{0}\right)$ and sodium sulphate $\left(\mathrm{Na}_{2} \mathrm{SO}_{4}\right)$, respectively. The mixtures (M1-M5) were: $\mathrm{M} 1=\mathrm{Na}_{2} \mathrm{~S}+\mathrm{FeS}_{2}+\mathrm{S}^{0}+\mathrm{Na}_{2} \mathrm{SO}_{4} ; \mathrm{M} 2=$ $\mathrm{Na}_{2} \mathrm{~S}+\mathrm{FeS}_{2}+\mathrm{S}^{0} ; \mathrm{M} 3=\mathrm{Na}_{2} \mathrm{~S}+\mathrm{FeS}_{2} ; \mathrm{M} 4=\mathrm{Na}_{2} \mathrm{~S}$ $+\mathrm{Na}_{2} \mathrm{SO}_{4}$; and $\mathrm{M} 5=\mathrm{FeS}_{2}+\mathrm{Na}_{2} \mathrm{SO}_{4}$. The samples were analysed without addition of ascorbic acid and ethanol and the results are presented in Fig. 3.

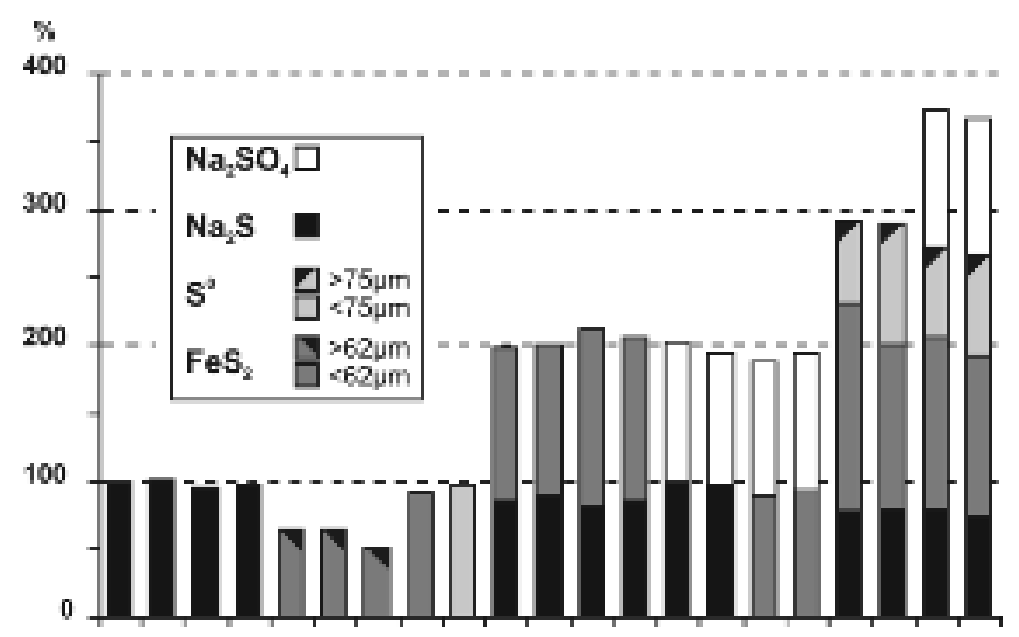

Fig. 3. Summed recoveries (\%) of sulphur species, separated individually and from mixtures (including different grain sizes). Ideally, each compound will show a (theoretical) recovery of $100 \%$, and the sum of e.g. four species equals $400 \%$. Deviations from $100 \%$ for an individual compound indicate cross-contamination between sulphur pools, or loss of sulphur. 
The recoveries for two different grain sizes of $\mathrm{FeS}_{2}(<62 \mu \mathrm{m}$ and $>62 \mu \mathrm{m})$ and $\mathrm{S}^{0}(<75 \mu \mathrm{m}$ and $>75 \mu \mathrm{m})$ show significant differences. For fine grained $\mathrm{FeS}_{2}$ the recovery was $90.4 \%$ but only 59.4 $\pm 6.4 \%(1 \mathrm{SD})$ for the coarser fraction. For $\mathrm{S}^{0}$ the results were similar, i.e. $96.2 \%$ and $71.9 \pm 11.0 \%$, respectively. However, grain sizes above $62 \mu \mathrm{m}$ for pyrite and elemental sulphur are extremely rare in natural sediments and AS soils, except for sites close to e.g. ore deposits.

The $\mathrm{Na}_{2} \mathrm{SO}_{4}$ was completely recovered (100.1 $\pm 1.1 \%$ ) from the mixtures (M1, M4 and M5), and apparently did not affect the recovery of other species. The $\mathrm{Na}_{2} \mathrm{~S}$ was completely recovered when separated individually $(98.4 \pm 2.2 \%)$ and with sulphate $(96.4 \%$ and $99.9 \%)$, but when separated in mixture with $\mathrm{FeS}_{2}$ (M3) only $85.4 \pm 2.9 \%$ was recovered, while the recovery of $\mathrm{FeS}_{2}$ was $118.5 \pm$ 7.7\%. However, the sum of $\mathrm{Na}_{2} \mathrm{~S}+\mathrm{FeS}_{2}$ in $\mathrm{M} 3$ $(203.9 \pm 5.5 \%)$ shows that a fraction of $\mathrm{Na}_{2} \mathrm{~S}$ was recovered in the $\mathrm{FeS}_{2}$ pool, explained by partial oxidation of $\mathrm{Na}_{2} \mathrm{~S}$ to elemental sulphur, subsequently extracted with the cold Cr-reduction. Similar results have been reported by Fossing and Jørgensen (1989).

In M1 and M2, the recovery of $\mathrm{FeS}_{2}$ was even larger $(130.5 \pm 14.2 \%)$, and it is likely that some of the "additional $\mathrm{FeS}_{2}$ " comes from original $\mathrm{S}^{0}$, and consequently that a small fraction of $S^{0}$ (presumably very fine grained) was reduced by the cold $\mathrm{Cr}$ reduction. The sum of recoveries for M1 (369.7 \pm $2.3 \%)$ and M2 $(290.0 \pm 1.0 \%)$ were slightly below the expected $400 \%$ and $300 \%$, respectively, and can be attributed to the large grain size of unreacted $S^{0}$. In all experiments with coarser fractions of $S^{0}(>75 \mu \mathrm{m})$, the dissolution of $S^{0}$ was incomplete even after 18 hours of distillation, compared to complete distillation after 4 hours using the finer fraction.

\section{Sulphur species in sediments}

When comparing the sum of reduced sulphur species (AVS, ES, CCrS and HCrS) with TRS in the potential AS soil and lake sediment (Table 1), there is an indication that little, or none, of the $\mathrm{H}_{2} \mathrm{~S}$ de- veloped from the individual distillation steps is lost during the process. It has previously been shown that $\mathrm{Cr}^{2+}$ does not reduce any significant quantities of sulphate or organic sulphur in sediments (e.g. Zhabina and Volkov 1978, Howarth and Jørgensen 1984, Canfield et al. 1986), and no excess $\mathrm{CCrS}$ or $\mathrm{HCrS}$ is expected from the $\mathrm{SO}_{4}{ }^{2-}$ pool. For sulphur species in the Överpurmo and Larsmo sediment CCrS comprised the largest pool (except for the Larsmo sample treated with ZnAc, where AVS was the largest pool), followed by AVS, $\mathrm{HCrS}, \mathrm{ES}$, and minor amounts of $\mathrm{SO}_{4}{ }^{2-}$ $(<0.01 \mathrm{wt} \%)$ and $\mathrm{OrgS}(<0.1 \mathrm{wt} \%)$. The concentration of TotS is somewhat lower than the combined sum of the separated sulphur species.

The recovery of AVS (Table 1) in the Överpurmo sample did not show any major differences whether using cold $6 \mathrm{M} \mathrm{HCl}(0.46 \pm 0.04 \mathrm{wt} \%)$, cold $6 \mathrm{M} \mathrm{HCl}$ and addition of $5 \mathrm{ml}$ of $0.1 \mathrm{M}$ ascorbic acid (AA) $(0.40 \pm 0.04 \mathrm{wt} \%)$ or heating of $6 \mathrm{M}$ $\mathrm{HCl}$ with addition of AA $(0.42 \pm 0.03 \mathrm{wt} \%)$. Pruden and Bloomfield (1968) showed that presence of $\mathrm{Fe}^{3+}$ in sediments could affect the determination of reduced sulphur by oxidizing $\mathrm{H}_{2} \mathrm{~S}$ to elemental sulphur in the reaction flask. To prevent this, $\mathrm{Fe}^{3+}$ is converted to $\mathrm{Fe}^{2+}$ by adding AA (Hsieh et al. 2002) or $\mathrm{SnCl}_{2}$ (Pruden and Bloomfield 1968) to the sample. Hsieh and Shieh (1997) noticed that addition of AA to a freeze-dried sediment increased recovery of AVS, but not in a fresh sample of the same sediment. This was probably due to the formation of $\mathrm{Fe}^{3+}$ during the freeze-drying, and that the fresh sediment only contained $\mathrm{Fe}^{2+}$. The reason why AA in this study did not have an effect was probably due to lack of reactive $\mathrm{Fe}^{3+}$ in the sediment. Amorphous FeS and mackinawite are completely dissolved in cold $6 \mathrm{M} \mathrm{HCl}$, while decomposition of greigite may be incomplete (Cornwell and Morse 1987). This, and possible formation of elemental sulphur during breakdown of greigite (Allen and Parkes 1995) requires harsher treatments (e.g. use of heat and/or a reducing agent). Addition of $\mathrm{SnCl}_{2}$ to the Överpurmo sample increased the recovery of AVS $(0.74 \pm 0.03 \mathrm{wt} \%)$ (Table 1), most likely due to the reduction of small amounts of disulphides (Cornwell and Morse 1987). Therefore AA, which is a milder reagent 
Vol. 14 (2005): 70-82.

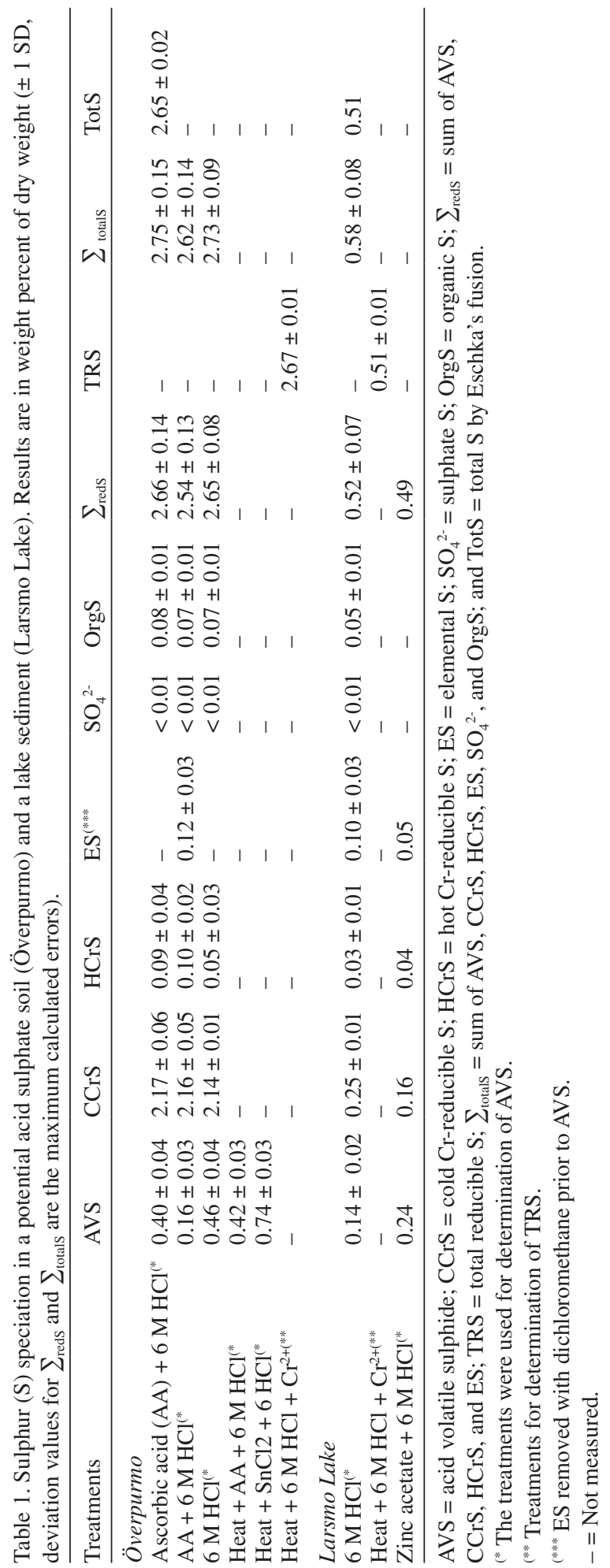


Backlund, K. et al. Determination of sulphur species in acid sulphate soils

but still effective in preventing $\mathrm{Fe}^{3+}$ interference (Hsieh et al. 2002), is proposed as the preferable reagent to use when analysing AS soil samples.

A major concern during sampling is the oxidation of AVS to elemental sulphur by atmospheric oxygen, leading to a lower AVS recovery and a higher ES recovery (or higher $\mathrm{HCrS}$ ). Addition of ZnAc will fix dissolved sulphides and AVS (monosulphides and possibly greigite) as the more stable $\mathrm{ZnS}$, which however will decompose as easily as the original reduced sulphur species during analysis (Morse et al. 1987, Duan et al. 1997). The addition of $\mathrm{ZnAc}$ to the Larsmo sample increased the AVS pool by approximately $42 \%$ to $0.24 \mathrm{wt} \%$, while the $\mathrm{CCrS}$ pool decreased by approximately $36 \%$ to $0.16 \mathrm{wt} \%$. This is possibly due to conversion of greigite to $\mathrm{ZnS}$, which means that no $\mathrm{S}^{0}$ is formed upon acid treatment in the analytical procedure. We therefore believe that the addition of $\mathrm{ZnAc}$ gives more accurate separations, and that consequently there is a risk that the CCrS pool for the Överpurmo sample is overestimated. Lasorsa and Casas (1996) noticed that addition of ZnAc may allow additional AVS to form in the sediment during storage for more than two weeks, and as a consequence, they recommended that $\mathrm{ZnAc}$ should not be used. We suggest, in contrast, that $\mathrm{ZnAc}$ could be admixed, prior to analysis, with the thawed sediment in order to prevent a proportion of greigite to end up in the $\mathrm{CCrS}$ pool. However, the assumed conversion of greigite to $\mathrm{ZnS}$ is not certain and should be verified in a separate experiment.

The HCrS pool in the Överpurmo and Larsmo samples did not show any major variations in recovery (Table 1). Since HCrS did not differ much, whether ES was removed or not, we consider that this is evidence for very little (or no) elemental sulphur in the sediments. The identified and quantified ES is probably the result of oxidation of AVS during analysis (i.e. after the addition of dichloromethane), sampling or storage.

\section{Sulphur-isotopic compositions}

Ideally, the distillation procedure recovers all of the sulphur in each species as $\mathrm{Ag}_{2} \mathrm{~S}$ or $\mathrm{BaSO}_{4}$ precipitates, thus allowing for analysis of the isotopic composition of each species. However, as shown above, there are several opportunities for overlap in the extraction of different species. Determining the isotopic composition of $\mathrm{Ag}_{2} \mathrm{~S}$ and $\mathrm{BaSO}_{4}$ precipitates collected in the speciation test above (mixtures M1 and M3-M5, Table 2) and comparing them to the original composition of the 'pure' compounds used tests for the effect on the isotopic composition of sulphur.

As the compounds chosen to represent the species AVS, CCrS, $\mathrm{HCrS}$ and $\mathrm{SO}_{4}{ }^{2-}$ were off-the-

Table 2. Isotopic compositions $\left(\delta^{34} \mathrm{~S}\right)$ and recovery (\%, in brackets) of sulphur $(\mathrm{S})$ containing chemical reagents $\left(\mathrm{Na}_{2} \mathrm{~S}\right.$ and $\left.\mathrm{Na}_{2} \mathrm{SO}_{4}\right)$ and natural sulphur minerals $\left(\mathrm{FeS}_{2}\right.$ and $\left.\mathrm{S}^{0}\right)$. The values for pure reagents were determined on individually prepared samples, while values for compounds are after separation from various mixtures. The analytical precision for $\delta^{34} \mathrm{~S}$ was estimated to $0.3 \%$.

\begin{tabular}{lcccc}
\hline Species & Acid volatile sulphide & Cold Cr-reducible $\mathrm{S}$ & Hot Cr-reducible S & Sulphate S \\
\hline Compounds & $\mathrm{Na}_{2} \mathrm{~S}$ & $\mathrm{FeS}_{2}$ & $\mathrm{~S}^{0}$ & $\mathrm{Na}_{2} \mathrm{SO}_{4}$ \\
\hline Pure reagents & 0.5 & 9.3 & 1.0 & 7.1 \\
$\mathrm{Na}_{2} \mathrm{~S}+\mathrm{FeS}_{2}+\mathrm{S}^{0}+\mathrm{Na}_{2} \mathrm{SO}_{4}$ & $-0.4(79.6)$ & $6.8(126.7)$ & $-0.5(65.9)$ & $7.7(99.7)$ \\
$\mathrm{Na}_{2} \mathrm{~S}+\mathrm{FeS}_{2}$ & $0.3(84.7)$ & $8.6(113.1)$ & - & - \\
$\mathrm{Na}_{2} \mathrm{~S}+\mathrm{FeS}_{2}$ & $0.1(89.4)$ & $8.8(110.4)$ & - & - \\
$\mathrm{Na}_{2} \mathrm{~S}+\mathrm{Na}_{2} \mathrm{SO}_{4}$ & $-0.3(99.9)$ & - & - & $7.0(101.6)$ \\
$\mathrm{Na}_{2} \mathrm{~S}+\mathrm{Na}_{2} \mathrm{SO}_{4}$ & $0.3(96.4)$ & $9.8(89.8)$ & - & $7.3(100.5)$ \\
$\mathrm{FeS}_{2}+\mathrm{SO}_{4}$ & - & $9.4(93.1)$ & - & $7.1(99.5)$ \\
$\mathrm{FeS}_{2}+\mathrm{SO}_{4}$ & - & & $7.5(101.2)$ \\
\hline
\end{tabular}

$-=$ Not measured. 
Vol. 14 (2005): 70-82.

shelf chemical reagents and mineral sulphides (Table 2), some inhomogeneity in $\delta^{34} \mathrm{~S}$ is probable. This, together with analytical error, may to some degree encroach upon the integrity of the data and the results may be regarded as tentative only. The differences in $\delta^{34} \mathrm{~S}$ values of the compounds were significantly large to reveal isotope mixing between critical pairs, but mixing of pairs with similar $\delta^{34} \mathrm{~S}$ and mixing with more than two members is impossible to be correctly estimated. Furthermore, the $\delta^{34} \mathrm{~S}$ value is defined on a one-dimensional scale and mixing between e.g. $\mathrm{FeS}_{2}-\mathrm{Na}_{2} \mathrm{~S}$ or $\mathrm{FeS}_{2}-\mathrm{S}^{0}$ in the same sample cannot in this case be discriminated. Therefore, the mixture M2 from the separation experiment above was excluded. With the exception of M1, the experiments were set up to reveal overlaps and mixing between pairs of species with significantly different $\delta^{34} S$ values.

Starting from an initial $\delta^{34} \mathrm{~S}$ value of $+0.5 \%$ o (Table 2), the extracted AVS ranges from $-0.4 \%$ o to $+0.3 \%$, a decrease slightly larger than the estimated analytical precision $( \pm 0.3 \%$ ) . With the exception of M4, the recovery of AVS and $\mathrm{HCrS}$ was low, and incomplete reaction may have caused fractionation of S-isotopes, and depletion of ${ }^{34} \mathrm{~S}$ in the emanated $\mathrm{H}_{2} \mathrm{~S}$ is probable. The $\mathrm{SO}_{4}{ }^{2-}$ was more or less quantitatively recovered in all experiments and, with the exception of M1 $\left(\delta^{34} \mathrm{~S}=7.7 \%\right.$ ) , the $\delta^{34} \mathrm{~S}$ of the extracts were similar $\left(\delta^{34} \mathrm{~S}=+7.0\right.$ $7.5 \%$ ) to that of the pure reagent $(7.1 \%$ ). This shows that the speciation method does not cause overlap involving $\mathrm{SO}_{4}{ }^{2-}$. However, the $\delta^{34} \mathrm{~S}$ of $\mathrm{CCrS}$ varies considerably and overlap between the other species is significant.

Mixture M1 contained all species and the results varied; recoveries of AVS and $\mathrm{HCrS}$ were low and $\mathrm{CCrS}$ was high, while the recovery of $\mathrm{SO}_{4}{ }^{2-}$ was close to $100 \%$ (Table 2). The $\delta^{34} \mathrm{~S}$ of $\mathrm{CCrS}$ showed a large decrease and, judging from the recoveries, the incorporated sulphur originated from AVS and $\mathrm{HCrS}$. The high $\delta^{34} \mathrm{~S}$ of the $\mathrm{SO}_{4}{ }^{2-}$ $(+7.7 \%)$ is somewhat mysterious; mass balance considerations suggest that the residual material of both AVS and $\mathrm{HCrS}$ should be roughly $+4 \%$ (assuming no crossover to $\mathrm{CCrS}$ ) and could not increase the value $+7.1 \%$ if mixed with $\mathrm{SO}_{4}{ }^{2-}$. The recovery also indicates that this is not a possibility, so more probably, it must be deemed analytical. In the binary mixtures M3 and M4, the recoveries of AVS and CCrS nearly added up to the expected $200 \%$ and mass balance was preserved. The recovery of $\mathrm{CCrS}$ in $\mathrm{M} 3$ was slightly high and the decrease in $\delta^{34} \mathrm{~S}$ was significant; the only possible contaminant in M3 was AVS and the overlap during distillation clearly affected the isotopic composition of CCrS. The recovery of AVS and $\mathrm{SO}_{4}{ }^{2-}$ was almost $100 \%$ for both species in M4, and no significant change was noted in the isotopic composition of either species (the low $\delta^{34} S$ in the first M4 AVS was probably caused by analytical error). In M5, there was no overlap between $\mathrm{CCrS}$ and $\mathrm{SO}_{4}^{2-}$, but there was some loss of $\mathrm{CCrS}$ that perhaps was coupled with fractionation of sulphur, as seen in one measurement with $\delta^{34} \mathrm{~S}$ of $+9.8 \%$ o.

The notably low recoveries and isotopic crosscontamination seen in the results are probably largely effects of grain size variation in the artificial samples prepared and attention must be given to diminution of the reagents in future experiments. However, we believe that this effect is limited to the artificial sample and that the more homogenous and finer grain size of clayey sediments results in better extraction of species (see Table 1) and less isotopic cross-contamination.

The isotopic compositions of sulphur species in the Överpurmo sediment are presented in Table 3. Duplicate samples were analysed in two parallel distillation lines and showed identical results within error, indicating the consistency of the method for extracting sulphur species for isotopic measurements from this type of sediments. The $\delta^{34} \mathrm{~S}$ values of the reduced sulphur species (AVS, $\mathrm{CCrS}$ and $\mathrm{HCrS}$ ) were similar and varied only within a small range $\left(\delta^{34} \mathrm{~S}=5.1-5.6 \%\right)$ while the value of $\mathrm{OrgS}$ was slightly lower $(4.1 \%$ ). The high $\delta^{34} \mathrm{~S}$ of the TotS $(6.0 \%$ ) was intriguing, but considering that the result of the TotS method (2.65 wt \%, Table 1, Överpurmo A) was less than the sum of the species $(2.75 \mathrm{wt} \%)$ in the same sample, it seems reasonable to believe that there is some loss of sulphur in the TotS method. Heating the sample with Eschka's mixture might cause volatilization of sulphur, leaving a residue slightly enriched in ${ }^{34} \mathrm{~S}$. 
Backlund, K. et al. Determination of sulphur species in acid sulphate soils

Table 3. Isotopic composition $\left(\delta^{34} \mathrm{~S}\right)$ of sulphur (S) species from the Överpurmo sediment. The analytical precision for $\delta^{34} \mathrm{~S}$ was estimated to $0.3 \%$.

\begin{tabular}{lccc}
\hline Species & $\delta^{34} \mathrm{~S}$ & Average $\delta^{34} \mathrm{~S}$ & $1 \mathrm{SD}$ \\
\hline \multirow{2}{*}{ Acid volatile sulphide } & 4.9 & & \\
& 5.4 & 5.1 & 0.25 \\
Cold Cr-reducible S & 5.4 & 5.1 & 0.24 \\
& 4.9 & & \\
Hot Cr-reducible S & 5.5 & 5.6 & 0.03 \\
& 5.6 & & \\
Organic S & 4.2 & 4.1 & 0.04 \\
Total S & 4.1 & & - \\
\hline
\end{tabular}

$-=$ Not measured.

The isotopic composition is used to study the relationship between sulphur species and can reflect the prevailing conditions during their formation. Reduced sulphur species (AVS, CCrS and $\mathrm{HCrS}$ ) commonly develop in this type of sediments through dissimilatory sulphate reduction, while OrgS may form by assimilatory sulphate reduction (incorporation into marine organisms). Sulphur assimilated by living organisms constitutes $0.5-3.0 \%$ of the dry weight (Dinur et al. 1980), and according to Kaplan et al. (1963) the maximum contribution of sulphur to the sediment from marine organisms (e.g. animals and algae) would be about one percent dry weight of the organic matter. Applying this reasoning to the Överpurmo sediment, where the content of organic matter was determined to $10.6 \%$, suggests that the sulphur (OrgS) incorporated in the organic matter would be about $0.1 \mathrm{wt} \%$. This is in agreement with the actual OrgS content of $0.07 \pm 0.02$ wt $\%$ determined in the Överpurmo sediment, and we propose that this sulphur originates from assimilatory sulphate reduction. Since the isotopic fractionation during assimilatory sulphate reduction is small, the organic sulphur in marine organisms (and terrestrial plants) should directly reflect the $\delta^{34} \mathrm{~S}$ isotopic ratio of the sulphate available in the growth environment (Dinur et al. 1980). At present, sulphate in freshwater has a $\delta^{34} S$ of $6 \pm 3 \%$ and $20 \pm$ $3 \%$ in seawater (Dinur et al. 1980), which indi- cates that the OrgS in the Överpurmo sediment may have been formed under the influence of freshwater. In a closed system sulphate will be completely reduced, yielding sulphides with similar $\delta^{34} \mathrm{~S}$ as the starting sulphate (Goldhaber and Kaplan 1980). The isotopic compositions of reduced sulphur species (AVS, CCrS and $\mathrm{HCrS}$ ) and organic sulphur (OrgS) in the sample thus further establish that the Överpurmo sediment was deposited in a freshwater environment.

\section{Conclusions}

The presented scheme provides a nearly complete analytical procedure for the separation and quantification of sulphur species present in boreal AS soils and in shallow coastal sediments. In order to optimize the analysis of sulphur species, the following must be considered: (1) separation and recovery of sulphur species is more accurate for finegrained samples (e.g. clayey sediments) but coarser material can be analysed if the procedures are adjusted for grain size effects (e.g. longer reaction times, harsher treatments); (2) if abundant, elemental sulphur can be analysed separately in a first step using dichloromethane; (3) ascorbic acid should be added to prevent $\mathrm{Fe}^{3+}$ from oxidizing $\mathrm{H}_{2} \mathrm{~S}$ to $\mathrm{S}^{0}$; and (4) addition of $\mathrm{ZnAc}$ improves the separation of AVS.

The $\mathrm{Ag}_{2} \mathrm{~S}$ and $\mathrm{BaSO}_{4}$ precipitates from the speciation procedure can further be analysed for the isotopic composition of sulphur, thus allowing for discussion of the origin of the sulphur species. With the suggested modifications, cross-contamination between sulphur species is reduced and when combined with isotopic data, the procedure is a useful tool for future studies of sulphur-rich sediments and boreal AS soils.

Acknowledgements. This research was financially supported by the Renlund Foundation, the Åbo Akademi Foundation, the Finnish Graduate School in Geology, the Magnus Ehrnroot Foundation and the Finnish Society of Sciences and Letters (the Sohlberg foundation). 


\section{References}

Allen, R.E. \& Parkes, R.J. 1995. Digestion procedures for determining reduced sulfur species in bacterial cultures and in ancient and recent sediments. In: Vairavamurthy, M.A. \& Schoonen, M.A.A. (eds.). Geochemical transformations of sedimentary sulfur. Washington DC, USA: American Chemical Society. p. 243-257.

Åström, M. 2001. Effect of widespread severely acidic soils on spatial features and abundance of trace elements in streams. Journal of Geochemical Exploration 73: 181191.

Bates, A.L., Spiker, E.C., Orem, W.H. \& Burnett, W.C. 1993. Speciation and isotopic composition of sulfur in sediments from Jellyfish Lake, Palau. Chemical Geology 106: 63-76.

Begheijn, L.Th., van Breemen, N. \& Velthorst, E.J. 1978. Analysis of sulfur compounds in acid sulfate soils and other recent marine sediments. Communications in Soil Science and Plant Analysis 9: 873-882.

Canfield, D.E., Boudreau, B.P., Mucci, A. \& Gundersen, J.K. 1998. The early diagenetic formation of organic sulfur in the sediments of Mangrove Lake, Bermuda. Geochimica et Cosmochimica Acta 62: 767-781.

Canfield, D.E., Raiswell, R., Westrich, J.T., Reaves, C.M. \& Berner, R.A. 1986. The use of chromium reduction in the analysis of reduced inorganic sulfur in sediments and shales. Chemical Geology 54: 149-155.

Cornwell, J.C. \& Morse, J.W. 1987. The characterization of iron sulfide minerals in anoxic marine sediments. Marine Chemistry 22: 193-206.

Dinur, D., Spiro, B. \& Aizenshtat, Z. 1980. The distribution and isotopic composition of sulfur in organic-rich sedimentary rocks. Chemical Geology 31:37-51.

Di Toro, D.M., Mahony, J.D., Hansen, D.J., Scott, K.S., Hicks, M.B., Mayr, S.M. \& Redmond, M.S. 1990. Toxicity of cadmium in sediments: the role of acid volatile sulfide. Environmental Toxicology and Chemistry 9: 1487-1502.

Duan, W.-M., Coleman, M.L. \& Pye, K. 1997. Determination of reduced sulphur species in sediments -an evaluation and modified technique. Chemical Geology 141: 185-194.

Fossing, H. \& Jørgensen, B.B. 1989. Measurement of bacterial sulfate reduction in sediments: Evaluation of a single-step chromium reduction method. Biogeochemistry 8: 205-222.

Georgala, D. 1980. Paleoenvironment studies of post-glacial black clays in north-eastern Sweden. Stockholm contributions in geology. p. 93-151.

Goldhaber, M.B. \& Kaplan, I.R. 1980. Mechanisms of sulfur incorporation and isotope fractionation during early diagenesis in sediments of the Gulf of California. Marine Chemistry 9: 95-143.

Hall, G.E.M., Pelchat, J.-C. \& Loop, J. 1988. Separation and recovery of various sulphur species in sedimentary rocks for stable sulphur isotopic determination. Chemical Geology: 35-45.

Howarth, R.W. \& Jørgensen, B.B. 1984. Formation of ${ }^{35}$ Slabelled elemental sulfur and pyrite in coastal marine sediments (Limfjorden and Kysing Fjord, Denmark) during short-term ${ }^{35} \mathrm{SO}_{4}{ }^{2-}$ reduction measurements. Geochimica et Cosmochimica Acta 48: 1807-1818.

Hsieh, Y.-P., Chung, S.-W., Tsau, Y.-J. \& Sue, C.-T. 2002. Analysis of sulfides in the presence of ferric minerals by diffusion methods. Chemical Geology 182: 195-201.

Hsieh, Y.P. \& Shieh, Y.N. 1997. Analysis of reduced inorganic sulfur by diffusion methods: improved apparatus and evaluation for sulfur isotopic studies. Chemical Geology 137: 255-261.

Joukainen, S. \& Yli-Halla, M. 2003. Environmental impacts and acid loads from deep sulfidic layers of two welldrained acid sulfate soils in western Finland. Agriculture, Ecosystems \& Environment 95: 297-309.

Kallmeyer, J., Ferdelman, T.G., Weber, A., Fossing, H. \& Jørgensen, B.B. 2004. A cold chromium distillation procedure for radiolabeled sulfide applied to sulfate reduction measurements. Limnology and Oceanography: Methods 2: 171-180.

Kaplan, I.R., Emery, K.O. \& Rittenberg, S.C. 1963. The distribution and isotopic abundance of sulphur in recent marine sediments off southern California. Geochimica et Cosmochimica Acta 27: 297-312.

Lasorsa, B. \& Casas, A. 1996. A comparison of sample handling and analytical methods for determination of acid volatile sulfides in sediment. Marine Chemistry 52: 211-220.

Morse, J.W. \& Luther, G.W., III. 1999. Chemical influences on trace metal-sulfide interactions in anoxic sediments. Geochimica et Cosmochimica Acta 63: 3373-3378.

Morse, J.W., Millero, F.J., Cornwell, J.C. \& Rickard, D. 1987. The chemistry of the hydrogen sulfide and iron sulfide systems in natural waters. Earth-Science Reviews 24: $1-42$.

Morse, J.W. \& Rickard, D. 2004. Chemical dynamics of sedimentary acid volatile sulfide. Environmental Science \& Technology, 38, 7: 131A-136A.

Mossmann, J.-R., Aplin, A.C., Curtis, C.D. \& Coleman, M.L. 1991. Geochemistry of inorganic and organic sulphur in organic-rich sediments from the Peru Margin. Geochimica et Cosmochimica Acta 55: 3581-3595.

Newton, R.J., Bottrell, S.H., Dean, S.P., Hatfield, D. \& Raiswell, R. 1995. An evaluation of the use of the chromous chloride reduction method for isotopic analyses of pyrite in rocks and sediment. Chemical Geology (Isotope Geoscience Section) 125: 317-320.

Nriagu, J.O. \& Soon, Y.K. 1985. Distribution and isotopic composition of sulfur in lake sediments of northern Ontario. Geochimica et Cosmochimica Acta 49: 823-834.

Öborn, I. 1994. Morphology, chemistry, mineralogy and fertility of some acid sulfate soils in Sweden. Ph.D. thesis, Swedish University of Agricultural Sciences, Uppsala, Sweden. 65 p.

Palko, J. 1994. Acid sulphate soils and their agricultural and environmental problems in Finland. Ph.D. thesis, University of Oulu, Finland. 58 p.

Poulton, S.W., Krom, M.D. \& Raiswell, R. 2004. A revised scheme for the reactivity of iron (oxyhydr)oxide minerals towards dissolved sulfide. Geochimica et Cosmochimica Acta 68: 3703-3715. 


\section{AGRICULTURAL AND FOOD SCIENCE}

Backlund, K. et al. Determination of sulphur species in acid sulphate soils

Pruden, G. \& Bloomfield, C. 1968. The determination of iron(II) sulphide in soil in the presence of iron(III) oxide. Analyst 93: 532-534.

Rice, C.A., Tuttle, M.L. \& Reynolds, R.L. 1993. The analysis of forms of sulfur in ancient sediments and sedimentary rocks: comments and cautions. Chemical $\mathrm{Ge}$ ology 107: 83-95.

Robinson, B.W. \& Kusakabe, M. 1975. Quantitative preparation of sulfur dioxide, for ${ }^{34} \mathrm{~S} /{ }^{32} \mathrm{~S}$ analyses, from sulfides by combustion with cuprous oxide. Analytical Chemistry 47: 1179-1181.

Skoog, D.A. \& West, D.M. 1976. Fundamentals of analytical chemistry. 3rd ed. Holt, Rinehart and Winston. $804 \mathrm{p}$.

Sullivan, L.A., Bush, R.T. \& McConchie, D.M. 2000. A modified chromium-reducible sulfur method for reduced inorganic sulfur: optimum reaction time for acid sulfate soil. Australian Journal of Soil Research 38: 729-734.

Sundström, R., Åström, M. \& Österholm, P. 2002. Comparison of the metal content in acid sulfate soil runoff and industrial effluents in Finland. Environmental Science \& Technology 36: 4269-4272.

Tuttle, M.L., Goldhaber, M.B. \& Williamson, D.L. 1986. An analytical scheme for determining forms of sulphur in oil shales and associated rocks. Talanta 33: 953-961.

van Breemen, N. 1973. Soil forming processes in acid sulphate soils. In: Drost, H. (ed.). Acid sulphate soil. International Institute for Land Reclamation and Improvement, Publication 18. p. 66-130.

Yanagisawa, F. \& Sakai, H. 1983. Thermal decomposition of barium sulfate-vanadium pentaoxide-silica glass mixtures for preparation of sulfur dioxide in sulfur isotope ratio measurements. Analytical Chemistry 55: 985-987.

Zhabina, N.N. \& Volkov, I.I. 1978. A method of determination of various sulfur compounds in sea sediments and rocks. In: Krumbein, W.E. (ed.). Environmental biogeochemistry and geomicrobiology. Michigan: Ann Arbor Science Publishers. p. 735-745. 